\title{
Secondary Parkinsonism
}

National Cancer Institute

\section{Source}

National Cancer Institute. Secondary Parkinsonism. NCI Thesaurus. Code C34899.

A condition with a clinical picture similar to that of Parkinson disease, but which is caused by external factors, including medication. 